\title{
On the Mechanism of the Murexide Reaction
}

\author{
Francisco Sánchez-Viesca ${ }^{*}$, Reina Gómez \\ Organic Chemistry Department, Faculty of Chemistry, National Autonomous University of Mexico, Mexico City (CDMX), Mexico \\ *Corresponding author: franviesca@yahoo.com
}

Received June 10, 2019; Revised July 20, 2019; Accepted July 29, 2019

\begin{abstract}
The murexide test used for identification of uric acid is mentioned in many laboratory texts. It consists in the degradative oxidation of uric acid by means of nitric acid and then a combination to yield a two ring product, purpuric acid. This gives a purple colour on addition of ammonia. From the chemical structure of the final product, various compounds are known to intervene for its obtention. However, the course of their formation during the degradation-oxidation process has not been cleared up. Thus, a mechanistic approach has been provided, step by step, in order to clarify the reaction sequence until the end product. Other compounds also formed are treated too. The study is based on well known reactivities and experimental observations.
\end{abstract}

Keywords: alloxan, alloxantin, dialuric acid, nitramines, parabanic acid, purpuric acid, uramil, uric acid

Cite This Article: Francisco Sánchez-Viesca, and Reina Gómez, "On the Mechanism of the Murexide Reaction." World Journal of Organic Chemistry, vol. 7, no. 1 (2019): 14-18. doi: 10.12691/wjoc-7-1-3.

\section{Introduction}

The murexide test for uric acid consists in the reaction of uric acid with dilute nitric acid, followed by ammonia addition: a purple colouration is produced due to the formation of ammonium purpurate or murexide. The reaction mixture is heated to dryness in a porcelain dish on the water bath. The ammonia is added to the residue when cold, [1-5].

Murexide was used as a dye for wool, and the uric acid was isolated from guano. Urea and parabanic acid are also formed in the dye synthesis.

However, the reaction mechanism of murexide formation has not been studied. So, we considered of interest to clear up the reactivities involved, continuing our studies on reaction mechanisms [6-10].

\section{Antecedents}

By the action of nitric acid, uric acid is converted to some extent into alloxantin, a molecular compound of alloxan and dialuric acid. Ammonia converts alloxantin into the ammonium salt of purpuric acid. Purpuric acid is readily hydrolyzed into alloxan and uramil [11,12], Figure 1.

Alloxan monohydrate has been prepared by chromic acid oxidation of benzalbarbituric acid in acetic acid, $[13,14]$. Figure 2.

There is an extense article on dialuric acid, 5-hydroxybarbituric acid, including preparation and results from different spectroscopic techniques. The compound is obtained by reduction of alloxan with hydrogen sulphide, [15]. Figure 3.<smiles>O=C1NC(=O)C(OC2(O)C(=O)NC(=O)NC2=O)C(=O)N1</smiles><smiles>N[14C]1=C([O-])[NH2+]C(=O)NC1=O</smiles>

Figure 1. Alloxantin and murexide structures

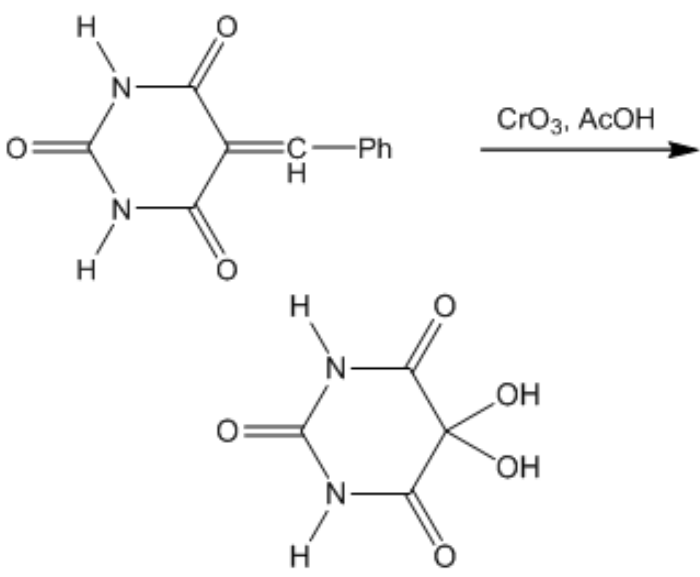

Figure 2. Preparation of alloxan monohydrate 


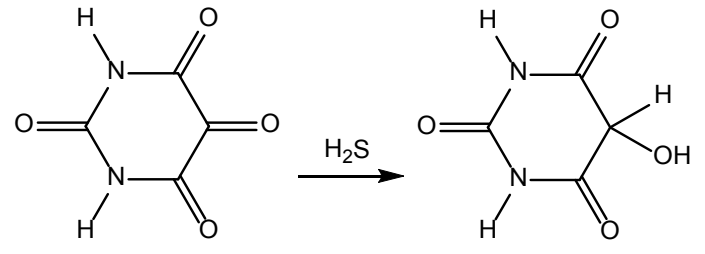

Figure 3. Obtention of dialuric acid

Alloxantin, the hemiketal formed between alloxan and dialuric acid has been prepared by partial reduction of alloxan with hydrogen sulphide, [16,17]. Figure 4

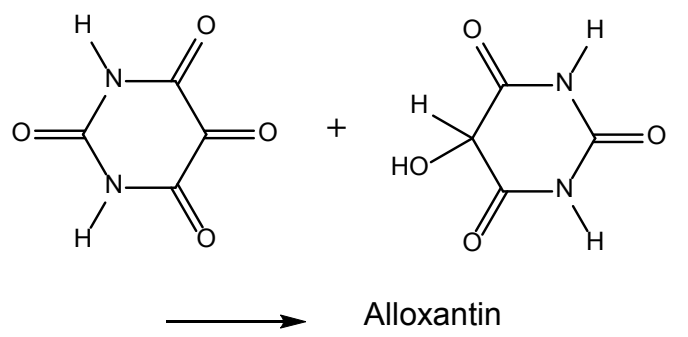

Figure 4. Condensation of alloxan with dialuric acid

Uramil, 5-aminobarbituric acid, is obtained from 5-nitrobarbituric acid [18] by reduction with tin and hydrochloric acid [19]. Figure 5.

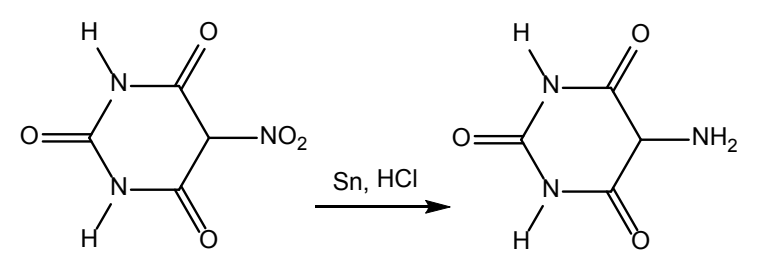

Figure 5. Obtention of uramil

As it can be seen, the communications refer to the chemical structures and to the preparations of the compounds related to the murexide.

The mechanism of the degradative oxidation of uric acid to murexide by means of nitric acid and ammonia has not been studied and we provide it in the next section. Other companion products are also considered.

\section{Discussion}

Murexide is the ammonium salt of purpuric acid. The disconnection approach to purpuric acid shows that the azomethine group comes from a carbonyl and an amino group. So, the direct precursors are 5-oxobarbituric acid (alloxan) and 5-aminobarbituric acid (uramil). Alloxan is the principal oxidation product of uric acid with nitric acid.

Uric acid is tautomeric and presents the lactam form (2,6,8-trioxopurine) and the lactim form (2,6,8-trioxopurine), Figure 6.

Uric acid crystallizes in the lactam form [20], computational chemistry also indicating that tautomer to be the most stable, [21].

The ureido groups are somewhat stable due to their resonance effect. The alloxan molecule presents four carbonyl groups in the pyrimidine ring and uric acid has only two carbonyls in this ring. Thus, acid catalyzed hydration of the double bond [22] provides a hydroxy group common to both rings, Figure 7 .<smiles>c1ncc2nc[nH]c2n1</smiles><smiles>O=c1[nH]c(=O)c2[nH]c(=O)[nH]c2[nH]1</smiles><smiles>Oc1nc(O)c2[nH]c(O)nc2n1</smiles>

Figure 6. Purine frame, and uric acid lactam and lactim forms<smiles>O=C1NC(=O)C2NC(=O)NC2(O)N1</smiles><smiles>OC1=NC2(O)NC(O)=NC2C(O)=N1</smiles>

Figure 7. Uric acid tautomeric forms after hydration

This pseudo hemiaminal can be visualized otherwise if the lactim forms are considered. There is a favourable structure, a carbinolamine, which is prone for reaction to proceed, i.e., carbonyl formation in the six member ring and ring opening of the five member ring, Figure 8.<smiles>NC(=O)NC1C(=O)NC(=O)NC1=O</smiles>

Figure 8. 5-Ureidobarbituric acid, intermediate

Acid hydrolysis of the ureido radical affords the unstable carbamic acid and 5-aminobarbituric acid, (uramil), one of our target molecules, Figure 9.

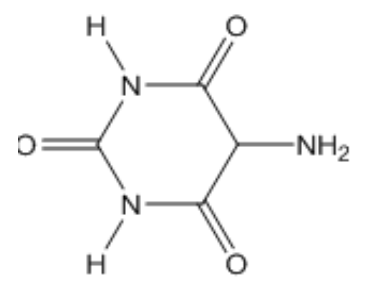<smiles>NC(=O)O</smiles>

Figure 9. Uramil, first component to murexide, and carbamic acid

The formation of 5-oxobarbituric acid (alloxan), the second target molecule, involves nitramine formation, Figure 10 .

Most nitramines eliminate the nitro group by means of acids yielding nitrous acid or nitrous oxide [23]. In the experimental part of murexide preparation, pots of 5 or 6 litre are used for only 1 litre of nitric acid, obviously for nitrous gas evolution [24].

Thus, protolysis of the nitramino group affords nitrous acid and an imine, which hydrolyses to a carbonyl, giving alloxan, Figure 11. 
<smiles>NC1CNC(=O)NC1=O</smiles><smiles>C1C[C@H]2CC[C@H]1O2</smiles><smiles>O=C1NC(=O)C(N[N+](=O)[O-])C(=O)N1</smiles>

Figure 10. 5-Nitraminobarbituric acid<smiles>O=C1NC(=O)C([NH2+][O-])C(=O)NC1=O</smiles><smiles>N=C1C(=O)NC(=O)NC1=O</smiles>

Figure 11. Nitramine degradation (redox step)

Finally, reaction of alloxan with uramil yields purpuric acid. Ammonia addition gives the purple colour of ammonium purpurate (murexide).

However this is not all since other products are also produced and this demands formation routes and reaction mechanisms. The additional compounds are urea, alloxantin and parabanic acid.

Urea must come from the pyrimidne ring in accordance with a secondary split, Figure 12.

Due to the electron density shift from the nitrogen to the oxygen, protonation of amides in acid solution occurs predominantly at the oxygen and not at the nitrogen [25]. Hydrolysis occurs via a tetrahedral intermediate after water addition. Proton exchange yields the carboxylic acid and ammonia, [26].

The kinetics of acid catalyzed hydrolysis of lactams indicates a tetrahedral intermediate, similar to that found for acyclic amide hydrolysis, involving acylium ion formation, [27].

Other component in the reaction medium is alloxantin, the hemiketal formed between alloxan and 5hydroxybarbituric acid (dialuric acid).

Thus, we must clear up the source of dialuric acid in the reaction medium. This may come from 5 -amino-barbituric acid by a van Slyke reaction [28], i.e., nitrosation, isomerization to the hydroxyazo group, nitrogen elimination by protolysis and reaction of the resulting carbocation with water. Figure 13.

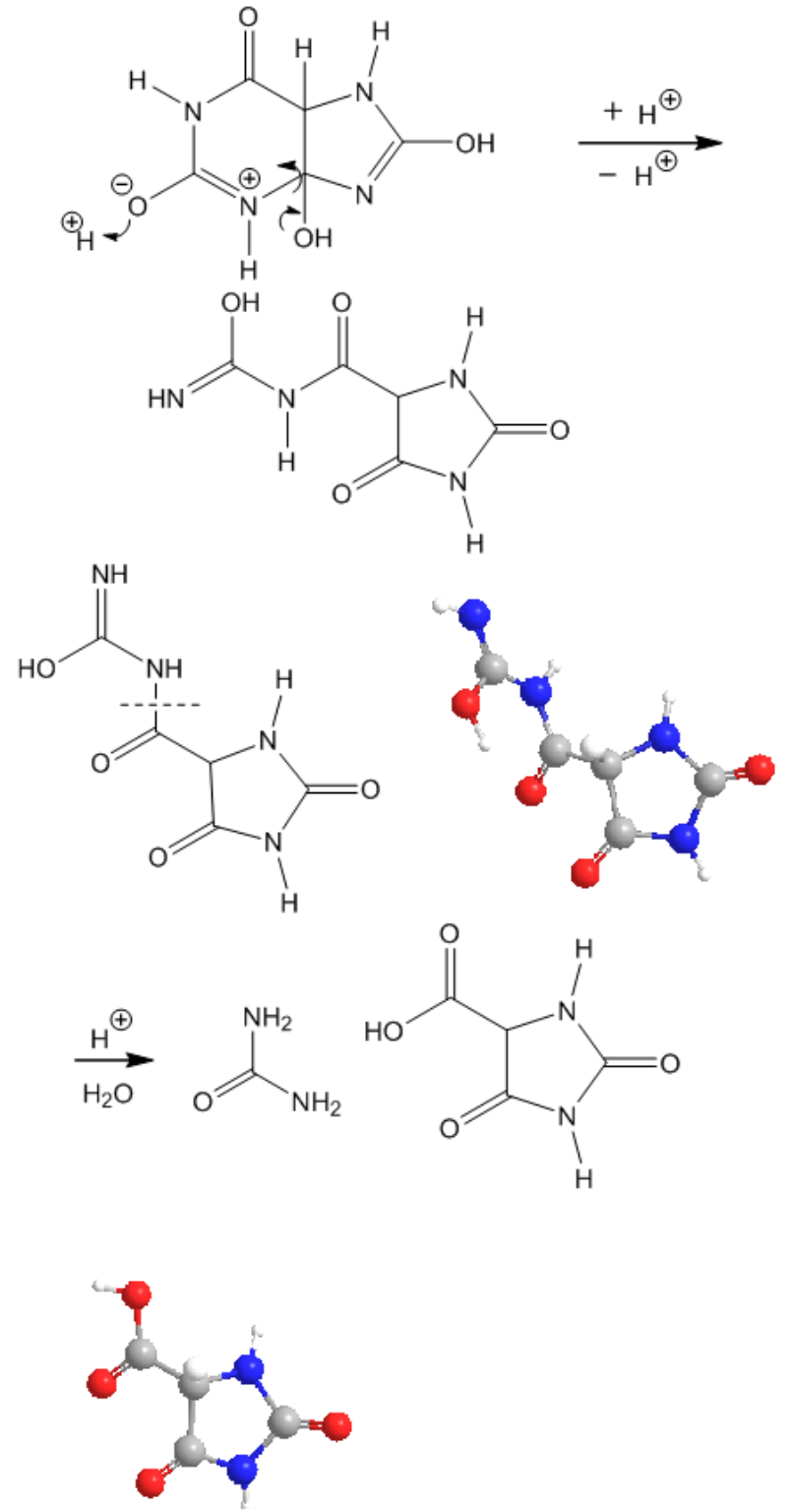

Figure 12. Pyrimidine ring opening and chain hydrolysis. 3D structures showing the preferred rotamers<smiles>[R]C([R])NN=O</smiles>

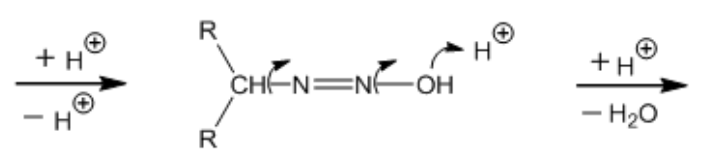<smiles>[R]C([R])OCCO</smiles>

Figure 13. Dialuric acid formation via van Slyke reaction

The presence of nitrous gases is observed experimentally, and they are produced during the nitramine degradation, as mentioned before. 
However, it has been found that, unexpectedly, 5-aminobarbituric acid (uramil) is susceptible of hydrolysis to dialuric acid, and better in the presence of alloxan or other oxidizing agents [29].

Thus, there are two ways to dialuric acid. Nevertheless, in the one pot experimental conditions, the nitrosylation reaction appears to be important.

The catalyzed hydrolysis of uramil was explained [29] by assuming the following reversible reaction:

Uramil + alloxan $=$ dialuric acid + alloxan imine

We propose the mechanism in Figure 14<smiles>NC1C(=O)NC(=O)NC1=O</smiles>

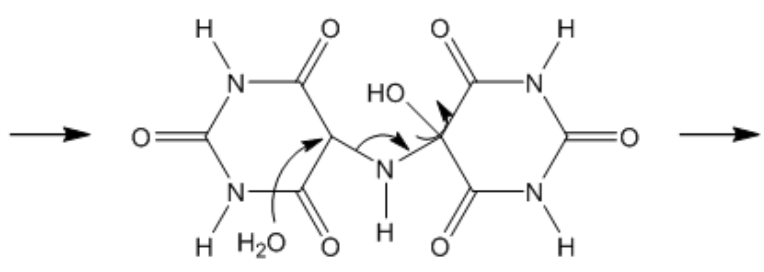<smiles>[2H]N=C1C(=O)NC(=O)NC1=O</smiles>

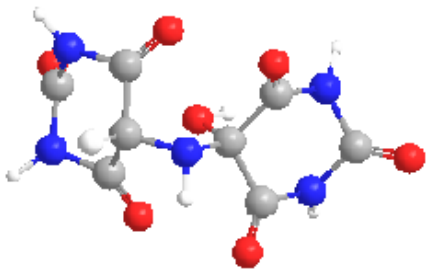

Figure 14. Assisted hydrolysis of uramil, and 3D structure showing the angular molecule of the hemiaminal

The hemiaminal as key intermediate is sustained because carbinolamines in five- or six-member rings are more stable than acyclic systems [30].

The proposed synchronous mechanism avoids a carbonium ion between two carbonyl groups.

Although alloxantin can be an intermediate in murexide formation, it is by no means the principal way to this dye since this route involves two extra steps: ammonolysis and condensation, Figure 15.

The direct route advanced above by us avoids these steps.

The enolate group in murexide has cross conjugation that adds to the system; besides lactim forms can extend conjugation. Thus, the purple colour of murexide can be explained by a chromophore, although being a salt, halochromism must also be considered. Figure 1.

Parabanic acid (oxalyl urea) is other compound found in the nitric acid oxidation of uric acid. It has been indicated that parabanic acid can also be prepared from alloxan and pretty strong nitric acid, [31].
Its presence as a secondary product in the general method starting from uric acid can be deduced since the specific Asche's method to prepare it is much more drastic [32]. He employs fuming nitric acid and several successive heatings. Uric acid is gradually added to nitric acid (d. 1.3) at $70^{\circ}$ and heated to dryness on the water bath; the residue is treated again two times with nitric acid (d. 1.4) and the residue crystallized from boiling water.<smiles>CC1([C@H](O)CN)C(=O)NC(=O)NC1=O</smiles><smiles>NC1C(=O)NC(=O)NC1=O</smiles><smiles>O=C1NC(=O)C(=Nc2c[nH]c(=O)[nH]c2=O)C(=O)N1</smiles>

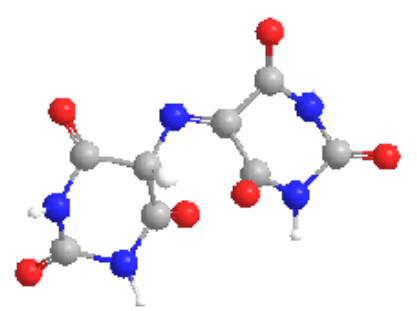

Figure 15. Purpuric acid 3D structure and formation from alloxantin<smiles>O=C1NC(=O)C(O)(O)C(=O)N1</smiles><smiles>NC(=O)NC(=O)C(O)(O)C(=O)O</smiles>

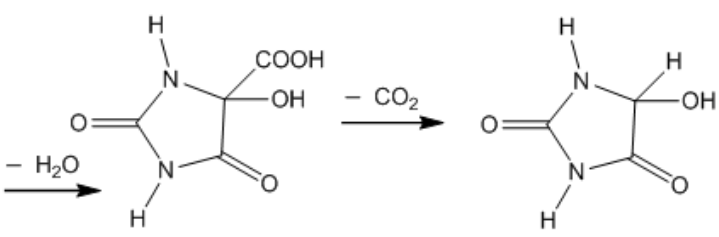

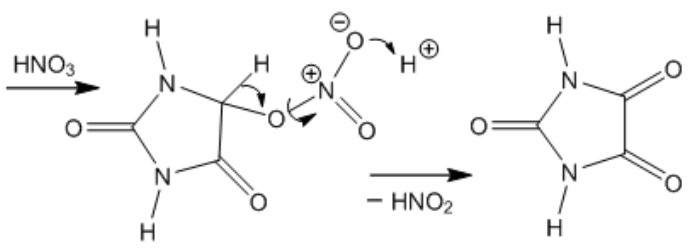

Figure 16. Steps to parabanic acid from alloxan monohydrate 
Our reaction mechanism starts from alloxan, making use of the above experimental information, Figure 16.

The alloxan monohydrate molecule presents two unsymmetrical imido groups. Due to electronic effects, hydrolysis favours cleavage of an acyl group vicinal only to one nitrogen atom, not the acyl group of the ureido, vicinal to two nitrogen atoms.

After ring opening, the very reactive gem diol is favourable to a 5-member ring closure, affording alloxanic acid. This has been obtained in alkaline medium in biological studies [33]. Decarboxylation yields a hemiaminal which is oxidized by nitric acid to carbonyl, giving parabanic acid.

\section{Conclusions}

We have provided reaction mechanisms for the series of steps occurring during the degradative oxidation of uric acid into purpuric acid.

The following reactions from uric acid to alloxan have been considered: double bond hydration, hemiaminal dissociation, hydrolysis, nitramine formation, degradation by protolysis, imine formation, and hydrolysis.

Other interesting point to treat is the presence of dialuric acid in the reaction medium. A possible route to this compound is via a van Slyke reaction, although it has been informed that, unexpectedly, uramil is susceptible of hydrolysis to dialuric acid. The pertinent mechanisms have been given.

Since we provide a direct route to purpuric acid, alloxantin is not a key intermediate since it requires dialuric acid, a secondary product, and two additional steps after alloxantin is formed, ammonolysis and condensation.

The purple colour of murexide has been looked from the chromophore point of view, and also as intervening halochromism.

The routes to other compounds isolated in the murexide large scale preparations were also taken into account and reaction mechanisms have been advanced.

The case of parabanic acid is of special interest. It involves alloxan hydrolysis, ring closure to hemiaminal, decarboxylation, hemiaminal nitrate, and oxidation via nitrous acid elimination by protolysis.

The study is based on insight and well known reactivities (nomothetic explanations).

\section{Acknowledgements}

Work dedicated to co-worker Martha Berros in her $50^{\text {th }}$ birthday.

\section{References}

[1] Agarwal, O. P., Advanced Practical Organic Chemistry, $26^{\text {th }}$ ed., GOEL Publishing House, Meerut, India, 2009, 58.
[2] Mann, F. G. and Saunders, B. Ch., Practical Organic Chemistry, $4^{\text {th }}$ ed., Longmans, London, 1962, 387.

[3] Cumming, W. M., Hopper, I. V. and Wheeler, T. Sh., Systematic Organic Chemistry, $4^{\text {th }}$ ed., Constable, London, 1950, 531.

[4] Gattermann, L. and Wieland, H., Laboratory Methods of Organic Chemistry, Macmillan, London, 1957, 136.

[5] Miall, S. and Miall, L. M., Diccionario de Química, 2a. ed., Atlante, Mexico City, 1953, 690.

[6] Sánchez-Viesca, F. and Gómez, R., "On the mechanism of indirubin formation in the Baeyer-Emmerling Synthesis", Am. J. Chem., 8(4), 85-89, 2018.

[7] Sánchez-Viesca, F. and Gómez, R., "On the mechanism of the Froehde Reaction", World J. Org. Chem., 7(1), 1-4, 2019.

[8] Sánchez-Viesca, F., Berros, M. and Gómez, R., "A Complete and sustained Clemmensen Reduction mechanism", Am. J. Chem., $8(1), 8-12,2018$

[9] Sánchez-Viesca, F., Berros, M. and Gómez, R., "On the mechanism of the Baeyer-Drewsen synthesis of indigo", Am. J. Chem., 6(1), 18-22, 2016.

[10] Sánchez-Viesca, F. and Gómez, R., "On the regiochemistry in the Heyns rearrangement", Am. J. Chem., 5(3), 86-89, 2015.

[11] Karrer, P., Organic Chemistry, $3^{\text {rd }}$. ed., Elsevier, New York, 1947, 804.

[12] Sharma, D. C. and Riyat, M., Practical Medicinal Biochemistry, B. I. Publications, New Delhi, 2007, 36.

[13] Hartman, W. W. and Sheppard, O. E., "Alloxan monohydrate", Org. Synth., 23, 3-5, 1943.

[14] Giral, F. and Rojahn, C. A., Productos Químicos y Farmacéuticos, Atlante, Mexico City, 1956, vol. 3, 1912-1916.

[15] Tipson, R. S. and Bretcher, L. M., "Reinvestigation of alloxantin and dialuric acid", J. Org. Chem., 16(7), 1091-1099, 1951.

[16] Nightingale, D.,"Alloxantin dihydrate”, Org. Synth., 23, 6-7, 1943.

[17] Vitoria, E., Prácticas Químicas, 7a. ed., Casals, Barcelona, Spain, $1953,522$.

[18] Ahluwalia, V. K., Bhagat, P., Aggarwal, R. and Chandra, R., Intermediates for Organic Synthesis, I. K. International, New Delhi, 2005, 281-282.

[19] Hartman, W. W. and Sheppard, O. E., "Uramil", Org. Synth., 12, $84-85,1932$.

[20] Ringertz, H., "The molecular and crystal structure of uric acid", Acta Crystallographica, 20(3), 397-403, 1966.

[21] Jiménez, V. and Alderete, J. B., "Theoretical calculations on the tautomerism of uric acid in gas phase and aqueous solution", J. of Molecular Structure: THEOCHEM, 755(1-3), 209-214, 2005.

[22] Bruice, P. Y., Organic Chemistry, $7^{\text {th }}$. ed., Pearson, Boston, 2014, 247.

[23] Hickinbottom, W. J., Reactions of Organic Compounds, $3^{\text {rd }}$. ed., Longmans, London, 1962, 470.

[24] The history and chemistry of the Murexide dye, http://www.chriscooksey.demon.co.uk/murexide/index.html Accessed: June 29, 2019.

[25] Millar, I. T. and Springall, H. D., A shorter Sidgwick's Organic Chemistry of Nitrogen, Clarendon, Oxford, 1969, 167-168.

[26] Breslow, R., Organic Reaction Mechanisms, Benjamin, New York, $1965,184$.

[27] Wan, P., Modro, T. A. and Yates, K., "The kinetics and mechanism of acid catalyzed hydrolysis of lactams", Can. J. Chem., 58(23), 2423-2432, 1980.

[28] Hill, G. A. and Kelley, L., Organic Chemistry, Blakiston, Philadelphia, 1948, 434.

[29] Davidson, D. and Epstein, E., "The murexide question", J. Org. Chem., 1(3), 305-314, 1936.

[30] Fleming, I., Ed., Comprehensive Organic Synthesis, Pergamon, Oxford, 2005, vol. 8, 249.

[31] Webster, J. W., A Manual of Chemistry, $3^{\text {rd }}$. ed., Marsh-CaponLyon-Webb, Boston, 1839, 428.

[32] Asche, A., "Über Parabansäure", Liebigs Ann. der Chem., 416(23), 226-228, 1918.

[33] Seligson, D. and Seligson, H.,"The conversion of alloxan to alloxanic acid in plasma", J. Biol. Chem., 190(2), 647-657, 1951. 